\title{
ANALISIS PENENTUAN POLA PRODUKSI UNTUK MEMINIMALISASI BIAYA PRODUKSI PADA PT SATYALOKA TIRTA AMERTA BANGLI
}

\author{
Ni Wayan Ernawati ${ }^{1}$ \\ I Gst Bgs Wirya Gupta ${ }^{2}$ \\ ${ }^{1,2}$ Fakultas Ekonomi Universitas Ngurah Rai, Bali, Indonesia \\ 1e-mail : ernakyuna94@gmail.com
}

\begin{abstract}
ABSTRAK
Penelitian ini bertujuan untuk mengetahui apakah pola produksi yang diterapkan oleh PT Satyaloka Tirta Amerta pada tahun 2018 dan untuk mengetahui efisiensi pola produksi yang telah diterapkan pada tahun 2018. Menggunakan analisis biaya tambahan atau analisis incremental cost yaitu pertimbangan biaya-biaya yang akan dikeluarkan bila menggunakan salah satu alternatif dari ketiga pola produksi. Hasil analisis, pola produksi yang diterapkan perusahaan adalah pola produksi moderat, dan dengan menggunakan ketiga pola produksi, melihat tambahan biaya yang dikeluarkan, ternyata penerapan pola produksi moderat pada perusahaan tidak efisien karena pola produksi moderat merupakan pola produksi yang memiliki biaya tambahan atau total incremental cost paling tinggi diantara ketiga pola produksi untuk tahun 2018.
\end{abstract}

Kata kunci : Pola Produksi Konstan, Pola Produksi Bergelombang dan Pola Produksi Moderat

\begin{abstract}
This study aims to determine whether the production pattern is applied by PT Satyaloka Tirta Amerta in 2018 and to determine the efficiency of production patterns that have been implemented in 2018. Using additional cost analysis or incremental cost analysis is a consideration of costs that will be incurred when using wrong one alternative from the three production patterns. The results of the analysis show that the production pattern applied by the company is a moderate production pattern, and by using the three production patterns, seeing the additional costs incurred, the application of moderate production patterns to companies is inefficient because moderate production patterns are production patterns that have additional costs or total incremental costs the highest among the three production patterns for 2018.
\end{abstract}

Keywords : Constant Production Patterns, Wavy Production Patterns and Moderate Production Patterns 


\section{PENDAHULUAN}

Pola produksi adalah distribusi dari produk tahunan ke dalam periode yang lebih kecil misalnya dalam mingguan, atau satuan waktu lainnya (Ahyari, 1995). Pola produksi merupakan penentuan kebijakan produksi perusahaan dalam melayani penjualan. Jika perusahaan merencanakan produksi untuk periode mendatang maka manajer produksi perlu menentukan berapa besarnya produksi yang harus dilaksanakan dalam setiap periodenya. Karena setiap perusahaan akan dihadapkan pada pola produksi yang berubah-ubah dari periode ke periode. Penentuan pola produksi ini bertujuan untuk mengoptimalkan biaya sehingga keuntungan akan semakin besar. Penentuan pola produksi ini merupakan hal yang sangat penting dalam merencanakan dan menentukan kebutuhan-kebutuhan pokok dalam berproduksi.

Perusahaan harus bisa memperkirakan penjualan produknya dalam satu periode agar perusahaan bisa merencanakan dan menentukan pola produksi yang tepat untuk memperoleh laba dan meminimumkan biaya. Untuk menentukan pola produksi yang tepat perusahaan harus menghitung Incremental Cost Analysis yaitu biaya tambahan yang akan terjadi di dalam proses produksi. Dalam suatu alternatif, biaya relevan merupakan biaya masa yang akan datang yang diperkirakan akan berbeda-beda atau terpengaruh oleh suatu pengambilan keputusan diantara berbagai macam alternative, (Mulyadi, 1984). Analisis ini dapat dipakai dalam menentukan laba yang optimal dengan biaya yang minimal. Ada tiga macam pola produksi yaitu: pola produksi konstan, pola produksi bergelombang dan pola produksi moderat.

Jika perusahaan menggunakan pola produksi konstan yang berarti jumlah produksi yang dihasilkan selalu sama dalam setiap satuan waktu akan menimbulkan masalah jika penjualan meningkat pesat karena perusahaan tidak mampu memenuhi kebutuhan konsumen. Sebaliknya apabila pada suatu waktu tertentu jumlah penjualan produk perusahaan mengalami penurunan, maka kelebihan produksi atas penjualan akan dimasukkan ke dalam gudang persediaan barang jadi, sehingga persediaan barang jadi akan bertambah. Dan jika menggunakan pola bergelombang yang jumlah produksinya mengikuti fluktuasi permintaan konsumen setiap periodenya yang mana perubahan jumlah penjualan akan diikuti oleh perubahan jumlah produksi. Pola produksi ini dapat dikatakan sebagai pola produksi yang menitik beratkan kepada stabilitas persediaan dimana tidak akan ada penumpukan barang jadi. Tetapi menyebabkan sulitnya bagi manajemen merencanakan kebutuhan bahan baku, tenaga kerja, dan fasilitasfasilitas produksi lain yang mendukung kelancaran proses produksi karena mengikuti jumlah penjualan. Sedangkan pola produksi moderat merupakan pola produksi yang berada di tengah-tengah antara pola produksi konstan dan pola produksi bergelombang. Apabila volume penjualan tinggi maka dapat dipenuhi dengan persediaan sehingga biaya perputaran tenaga kerja tidak setinggi pada pola produksi bergelombang dan apabila volume penjualan rendah maka biaya penyimpanan tidak setinggi pada pola produksi konstan. Maka dari itu pentingnya sebuah perusahaan untuk menentukan pola produksi. PT 
Satyaloka Tirta Amerta adalah sebuah perusahaan industri air minum dalam kemasan (AMDK) dengan merk SANGSANG dan ASTY yang terletak di Banjar Buungan, Desa Tiga, Kecamatan Susut, Kabupaten Bangli. Industri air minum yang berada di ketinggian \pm 1.300 $m$ diatas permukaan laut dengan kawasan yang masih natural, jauh dari kepadatan penduduk dan tidak ada limbah-limbah industri kimia sehingga air baku kami sangat natural, sejuk dan bebas dari pencemaran.

Air yang merupakan sumber kehidupan bagi manusia semakin sulit untuk di raih. Kebutuhan air bersih siap minum menjadi sesuatu yang begitu penting saat ini. Salah satu cara untuk mengatasi masalah perolehan air bersih yang aman bagi kesehatan adalah melalui produksi air minum mineral yang di buat oleh perusahaan air minum. Kebutuhan air minum yang bersih dan sehat meningkat pesat seiring dengan meningkatnya pertumbuhan penduduk menyebabkan banyaknya pesaing yang muncul. Kondisi ini menuntut setiap perusahaan air mineral berusaha keras untuk memenuhi permintaan konsumen. Untuk memenuhi permintaan konsumen perusahaan harus menentukan pola produksi yang benar supaya tidak menimbulkan masalah. Begitu pula dengan PT. Satyaloka Tirta Amerta yang mengalami masalah dengan pola produksi yang berubah-ubah dan berpacu dengan pesanan konsumen. Untuk dapat menentukan pola produksi yang tepat, diperlukan perhitungan berdasarkan metode akuntansi yang tepat dengan menggunakan metode Incremental Cost Analysis. Metode ini merupakan tambahan biaya yang akan terjadi jika perusahaan memilih alternatif keputusan tertentu.
Penelitian ini bertujuan untuk mengetahui: pola produksi yang diterapkan pada PT. Satyaloka Tirta Amerta dalam proses produksinya pada tahun 2018 dan untuk mengetahui pola produksi yang diterapkan oleh PT. Satyaloka Tirta Amerta dalam proses produksinya pada tahun 2018 sudah efisien.

\section{METODE PENELITIAN}

Penelitian ini menggunakan desain penelitian metode kuantitatif yaitu penelitian yang menekankan analisisnya pada data numerical atau angka yang akan memecahkan masalah pola produksi dengan menggunakan data-data dari volume produksi, volume penjualan dan tambahan biaya-biaya pada PT Satyaloka Tirta Amerta periode Januari sampai Desember 2018 dan akan dianalisis menggunakan ketiga pola produksi. Teknik pengumpulan data dalam penelitian ini dilakukan dengan observasi, wawancara dan dokumentasi. Teknik analisis data penelitian ini menggunakan metode analisis incremental cost yang digunakan untuk mengetahui besarnya biaya tambahan bila menggunakan pola produksi tertentu. Untuk menghitung biaya tambahan dapat dilakukan langkahlangkah sebagai berikut (Mulyadi. 1984): Menghitung rata-rata persedian per bulan

Total Persedian akhir : 12 = rata-rata persediaan per bulan.

Menghitung biaya pemeliharaan produk yang di simpan per satuan unit

$\frac{\text { Biaya pemeliharaan per bulan }}{\text { rata-rata persediaan ber bulan }}=$ biaya pemeliharaan per unit

Menghitung biaya- biaya tambahan yang akan terjadi tahun 2018 

Biaya Simpan
pemeliharaan $\left\{\frac{Q}{2}\right.$ x biaya $\}$

Hitung biaya tambahan
menggunakan pola
konstan, bergelombang dan moderat.

\section{HASIL DAN PEMBAHASAN}

Tahap awal yang dilakukan adalah mengambil data produksi dan penjualan aktual yang terjadi pada PT Satyaloka Tirta Amerta tahun 2018

\section{Tabel 1}

\section{Persediaan, Tingkat Produksi, Volume Penjualan Tahun 2018}

\begin{tabular}{|c|c|c|c|c|}
\hline Duan & Perstedns and & Profiky & Peniusian & $\begin{array}{c}\text { Persedaan } \\
\text { Aithe }\end{array}$ \\
\hline innan & 58,789 & $74,679.02$ & $82,060.50$ & $91,40 \mathrm{~A}$ \\
\hline Februari & $91,40 \mathrm{3}$ & $8,162.03$ & $0 ., 452.50$ & 112,117 \\
\hline Maret & 112.117 & $104,397.27$ & 92.459 .50 & 124,046 \\
\hline Apri & 124,066 & 73.185 .42 & 0.159 .60 & 117,072 \\
\hline Mei & 117,072 & $74,198.26$ & $77,457.50$ & 109,813 \\
\hline juni & 169,813 & $102,310.23$ & $112,133 . \pi 0$ & 99,989 \\
\hline IIIE & 50,883 & $7,666.16$ & $85,025.50$ & $\$ 2.624$ \\
\hline Agesgur & 92629 & $75,425,73$ & 02019.60 & 65.245 \\
\hline September & 65.265 & $75,275,90$ & 57.135 .60 & 203,995 \\
\hline gatoket. & 103.390 & $04,970.73$ & 71.421 .50 & 96.544 \\
\hline Novembes & 90,944 & $71,631.84$ & $79,140.00$ & $B 9 A 96$ \\
\hline Desember & 89,496 & $06,464.31$ & $73,222.50$ & 62,739 \\
\hline TOTAL & 12200.544 & 342,41631 & 257.467 .20 & 1.204989 \\
\hline
\end{tabular}

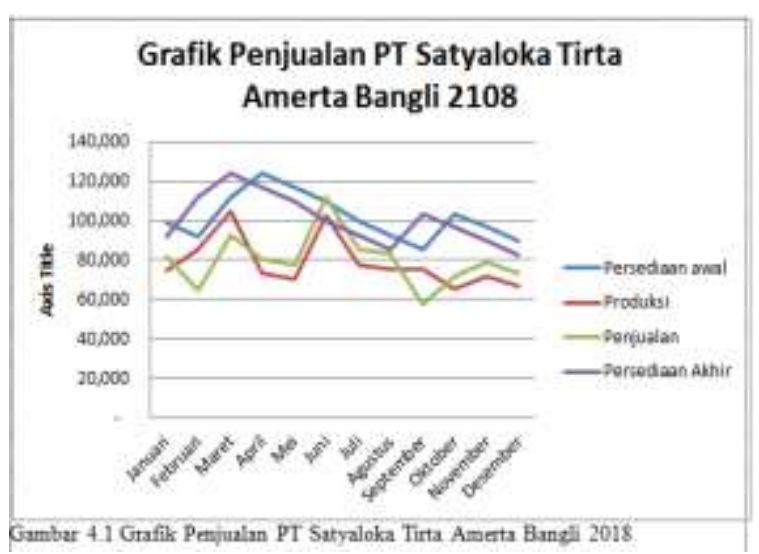

Berdasarkan tabel 1 dan digambarkan secara grafik dapat dilihat PT Satyaloka Tirta Amerta Bangli menggunakan pola produksi moderat dalam proses produksinya tahun 2018 karena jumlah produksi dalam beberapa periode tertentu konstan dan dalam periode tertentu mengalami kenaikan untuk konstan kembali yang akan dianalisis dalam masalah yang kedua adalah untuk mengetahui apakah pola produksi yang diterapkan PT Satyaloka Tirta Amerta efisien atau tidak. 
Tabel 2

Tingkat Persediaan dan Rata-rata Persediaan 2018

\begin{tabular}{|c|c|c|c|}
\hline Bulan & $\begin{array}{c}\text { Persediaan } \\
\text { awal }\end{array}$ & $\begin{array}{c}\text { Persediaan } \\
\text { Akhir }\end{array}$ & $\begin{array}{l}\text { Rata-Rata } \\
\text { Persediaan }\end{array}$ \\
\hline Januari & 98,789 & 91,498 & 95,058 \\
\hline Februari & 91,408 & 112,117 & 101,762 \\
\hline Maret & 112,117 & 124,046 & 118,081 \\
\hline April & 124,045 & 117,072 & 120,559 \\
\hline Mei & 113,072 & 109,813 & 113,443 \\
\hline Juni & 109,813 & 99,989 & 104,901 \\
\hline ful & 99,989 & 92,629 & 96,309 \\
\hline Agustus & 92,629 & 85,245 & 88,937 \\
\hline September & 85,245 & 103,335 & 94,320 \\
\hline Ohtober. & 103,395 & 96,944 & 100,170 \\
\hline November & 96,944 & 89,496 & 93,220 \\
\hline Desember & 89,496 & 82,738 & 85,117 \\
\hline TOTAL & $1,220,944$ & $1,204,893$ & $1,212,919$ \\
\hline
\end{tabular}

Berdasarkan data tabel 2 rata-rata tingkat persediaan per bulan adalah sebesar persediaan awal + persediaan akhir dibagi 2. Selanjutnya dari total rata-rata persediaan dibagi 12. maka rata-rata persedian per bulan adalah sebesar

\subsubsection{9 unit : $12=101.076$ unit}

Selanjutnya dapat dipaparkan untuk mencari tambahan biaya-biaya yang terjadi pada tahun 2018 adalah sebagai berikut :

\section{a.Biaya Simpan}

Berdasarkan data yang didapatkan pada tahun 2018 perusahaan mengalokasikan untuk biaya simpan rata-rata per bulan adalah sebesar Rp.205.000. Untuk biaya pemeliharaan per bulan perusahaan mengalokasikan biaya sebesar Rp.2.250.000. Untuk mendapatkan biaya simpan pada tahun 2018 dapat dilihat dari alokasi biaya simpan per bulan, biaya pemeliharaan per bulan dan rata-rata persediaan per bulan nya. Selanjutnya untuk menghitung biaya pemeliharaan persediaan yang disimpan adalah biaya pemeliharaan per bulan dibagi rata-rata persediaan per bulan.

Jadi biaya pemeliharaan persediaan produk yang disimpan adalah $\frac{\text { Rp.2.250.000 }}{101.076}=22.26$ per unit

\section{b.Biaya Perputaran Tenaga Kerja}

PT. Satyaloka Tirta Amerta tidak melakukan perputaran tenaga kerja perusahaan hanya memakai pegawai dan staff nya dalam berproduksi pada tahun 2018. Jadi biaya perputran tenaga kerja tidaka ada atau sebesar Rp.0.

\section{c. Biaya Lembur}

Biaya ini terjadi apabila jumlah produk yang diproduksi melebihi kapasitas normal yang ditetapkan perusahaan yaitu 200.000 unit per bulan. Adapaun biaya lembur yang ditetapkan perusahaan apabila terjadi lembur adalah Rp.500 per unit.

\section{d. Biaya Sub Kontrak}

PT Satyaloka Tirta Amerta dalam produksinya untuk tahun 2018 tidak melebihi kapasitas maksimal dan perusahaan dapat memenuhi sendiri 
permintaan pasar. Jadi biaya sub kontraknya adalah sebesar Rp.0..

Setelah biaya-biaya yang diterapkan perusahaan diketahui, selanjutnya dihitung tambahan biaya yang terjadi di tahun 2018 yaitu sebagai berikut : a. Biaya Simpan

Untuk menghitung biaya simpan dilakukan dengan menggunakan rumus : $\underset{\text { pemeliharaan }}{\text { biaya simpan }}\left\{\left(\frac{Q}{2}\right) \times\right.$ biaya

Ket : Q = Persediaan awal+Persediaan Akhir

Tabel 3

Total Biaya Tambahan 2018

\begin{tabular}{|l|c|}
\hline \multicolumn{1}{|c|}{ Biaya Tambahan } & Jumlah \\
\hline Biaya Simpan & 29.459 .566 \\
\hline Biaya Perputaran Tenaga Kerja & - \\
\hline Biaya Lembur & - \\
\hline Biaya Sub Kontrak & - \\
\hline TOTAL & 29.459 .566 \\
\hline
\end{tabular}

Sumber: Data Primer Diolah

Sesudah menghitung tambahan biaya yang terjadi tahun 2018, kemudian akan dihitung biaya tambahan dengan menggunakan ketiga pola produksi yang berkaitan dengan pola produksi konstan, bergelombang dan pola produksi moderat. Dari hasil ketiga produksi yang bersangkutan nantinya akan dapat digunakan untuk menjawab masalah apakah pola produksi yang diterapkan PT Satyaloka Tirta Amerta Bangli sudah efisien.

Tabel 4

Persediaan, Tingkat Produksi, Penjualan Pada Pola Produksi Konstan 2018

\begin{tabular}{|c|c|c|c|c|}
\hline Balan & $\begin{array}{c}\text { Persedians } \\
2 w 2 \text {. }\end{array}$ & Produks & Penivalan & $\begin{array}{l}\text { Pessedizm } \\
\text { Akhit }\end{array}$ \\
\hline Jancarí & 96,789 & 79.788 .99 & $82,060.50$ & 96,51 \\
\hline Feturai & 96,517 & 79,78893 & $64,452.50$ & 111.85 \\
\hline Neros & 111,854 & $79,788.93$ & $92,458,50$ & 99.18 \\
\hline Apri & 99,184 & 79,788993 & 80.159 .00 & 98.81 \\
\hline $\mathrm{Ma}$ & 98,814 & $79,788.93$ & $77,457.50$ & 101,14 \\
\hline Juni & 101.146 & 79,78893 & 112133.70 & 68.801 \\
\hline Juli & 68,801 & $79,788.93$ & 85,02650 & $63,56$. \\
\hline Aqustus & 63,563 & $79,788.93$ & 8281000 & 60.54 \\
\hline Septembet & 60,542 & $79,788.93$ & $57,125.00$ & $83,20 \mathrm{t}$ \\
\hline Otasber & 83,206 & 79,78893 & $71,421.50$ & $91,57$. \\
\hline Nevenbet & 91.574 & $79,788.93$ & $79,140.00$ & 92,22 \\
\hline Descmber & 92,223 & 79.78893 & 73,22250 & 98,789 \\
\hline TOTAL & $1,066,213$ & 957,46720 & $957,467.20$ & $1,066,21$ \\
\hline
\end{tabular}


Berdasarkan tabel 4 pada pola produksi konstan. pola produksi ini merupakan suatu distribusi tahunan ke dalam produksi bulanan dimana jumlah produksi per bulan nya adalah sama. maka data pada tabel diatas dapat dihitung dari nilai total penjualan dibagi 12 bulan dengan perhitungan sebagai berikut :

957.467.20 unit : $12=79.788,93$ unit.

Tabel 5

Total Biaya Tambahan Pada Pola Produksi Konstan 2018

\begin{tabular}{|l|c|}
\hline \multicolumn{1}{|c|}{ Biaya Tambahan } & Jumlah \\
\hline Biaya Simpan & 26.193 .910 \\
\hline Biaya Perputaran Tenaga Kerja & 0 \\
\hline Biaya Lembur & 0 \\
\hline Biaya Sub Kontrak & 0 \\
\hline TOTAL & 26.193 .910 \\
\hline
\end{tabular}

Sumber: Data Primer Diolah

Tabel 6

Total Biaya Tambahan Pada Pola Produksi Konstan 2018

\begin{tabular}{|c|c|c|c|c|}
\hline Bulan & $\begin{array}{c}\text { Persediaan } \\
\text { awal }\end{array}$ & Produksi & Penjualan & $\begin{array}{c}\text { Persadiaan } \\
\text { Akhir }\end{array}$ \\
\hline Januari & 98,789 & $82,060,50$ & $82,060.50$ & 98,789 \\
\hline Februari & 98,789 & 64,45250 & $64,452.50$ & 98,789 \\
\hline Maret & 98,789 & $92,458,50$ & $92,458.50$ & 98,789 \\
\hline April & 98,789 & $80,159.00$ & $80,159.00$ & 98,789 \\
\hline $\mathrm{Met}$ & 98,789 & 77,45750 & $77,457,50$ & 98,789 \\
\hline Juni & 98,789 & $112,133,70$ & $112,133.70$ & 98,789 \\
\hline Juli & 98,789 & 85,02650 & $85,026.50$ & 98,799 \\
\hline Agustus & 98,789 & $82,810.00$ & $82,810.00$ & 98,789 \\
\hline September & 98,789 & $57,125,00$ & $57,125.00$ & 98,789 \\
\hline Ostober & 98,789 & $71,421,50$ & 71,42150 & 98,789 \\
\hline November & 98,789 & $79,140,00$ & $79,140.00$ & 98,789 \\
\hline Desember & 98,789 & 73,22250 & $73,222.50$ & 98,789 \\
\hline TOTAL & $1,185,468$ & $957,467.20$ & $957,467.20$ & $1,185,468$ \\
\hline
\end{tabular}


Tabel 7

Total Biaya Tambahan Pada Pola Produksi Bergelombang 2018

\begin{tabular}{|l|r|}
\hline \multicolumn{1}{|c|}{ Biaya Tambahan } & Jumlah \\
\hline Biaya Simpan & 28.848 .518 \\
\hline Biaya Perputaran Tenaga Kerja & - \\
\hline Biaya Lembur & - \\
\hline Biaya Sub Kontrak & - \\
\hline TOTAL & 28.848 .518 \\
\hline
\end{tabular}

Sumber: Data Primer Diolah

Tabel 8

Persediaan, Tingkat Produksi, Penjualan Pada Pola Produksi Moderat Tahun 2018

\begin{tabular}{|l|c|c|c|c|}
\hline \multicolumn{1}{|c|}{ Bulan } & $\begin{array}{c}\text { Persediaan } \\
\text { awal }\end{array}$ & Produksi & Peniualan & $\begin{array}{c}\text { Persediaan } \\
\text { Akhir }\end{array}$ \\
\hline Januari & $98,789.00$ & $73,256.50$ & $82,060.50$ & $89,985.00$ \\
\hline Februari & $89,985.00$ & $73,256.50$ & $64,452.50$ & $98,789.00$ \\
\hline Maret & $98,789.00$ & $86,308.75$ & $92,458.50$ & $92,639.25$ \\
\hline April & $92,639.25$ & $86,308.75$ & $80,159.00$ & $98,789.00$ \\
\hline Mai & $98,789.00$ & $94,795.60$ & $77,457.50$ & $116,127.10$ \\
\hline Juni & $116,127.10$ & $94,795.60$ & $112,133.70$ & $98,789.00$ \\
\hline Jull & $98,789.00$ & $83,918.25$ & $85,026.50$ & $97,680.75$ \\
\hline Agustus & $97,680.75$ & $83,918.25$ & $82,810.00$ & $98,789.00$ \\
\hline September & $98,789.00$ & $64,273.25$ & $57,125.00$ & $105,937.25$ \\
\hline Oktober & 105937.25 & $64,273.25$ & $71,421.50$ & $98,789.00$ \\
\hline November & $98,789.00$ & $76,181.25$ & $79,140.00$ & $95,830.25$ \\
\hline Desember & $95,830.25$ & $76,181.25$ & $73,222.50$ & $98,789.00$ \\
\hline TOTAL & $1,190,934$ & $957,467.20$ & $957,467.20$ & $1,190,934$ \\
\hline
\end{tabular}

Sumber: Data Primer Diolah

Untuk menghitung produksi tahun 2018 pada pola produksi moderat adalah dengan cara menjumlahkan penjualan bulan pertama ditambah dengan penjualan bulan kedua dibagi 2 . begitupula selanjutnya di bulan berikutnya. Untuk perhitungan produksi pada pola produksi moderat adalah sebagai berikut :

1. 2 bulan $\mathrm{I}=$ $\frac{82.060,50+64.452,50}{2}=73.256,50$
2. 2 bulan II $=\frac{92.458,50+80.159}{2}=$ $86.308,75$

3. 2 bulanIII $=\frac{77 \cdot 457,50+112 \cdot 133,70}{2}=$ 94.795,60

4. 2 bulan IV $=\frac{85.026,50+82.810}{2}=$ $83.918,25$

5. 2 bulan $\mathrm{V}=\frac{57 \cdot 125+71.421,50}{2}=$ $64.273,25$

6. 2 bulan $\mathrm{VI}=\frac{79.140+73 \cdot 222,50}{2}=$ $76.181,25$ 
Tabel 9

Total Biaya Tambahan Pada Pola Produksi Moderat Tahun 2018

\begin{tabular}{|c|c|}
\hline Biaya Tambahan & Jumlah \\
\hline Biaya Simpan & $28.970 .181,94$ \\
\hline Biaya Perputaran Tenaga Kerja & - \\
\hline Biaya Lembur & - \\
\hline Biaya Sub Kontrak & - \\
\hline TOTAL & $28.970 .181,94$ \\
\hline
\end{tabular}

Tabel 10

Perbandingan Biaya Tambahan Pola Produksi Konstan, Bergelombang dan Moderat Tahun 2018

\begin{tabular}{|c|c|c|c|}
\hline Analisis Biara & $\begin{array}{c}\text { Pola Prodithsil } \\
\text { Konstan }\end{array}$ & $\begin{array}{l}\text { Pola Produlksi } \\
\text { Bergelombarg }\end{array}$ & $\frac{\text { Pola Produksi }}{\text { Bsoderat }}$ \\
\hline Biava Simpan & $26,193,910.28$ & $28,848,517.68$ & $28970,181.94$ \\
\hline $\begin{array}{l}\text { Biava Perputarn Tenaga } \\
\text { Keria }\end{array}$ & - & - & - \\
\hline Biara Lembur & - & - & - \\
\hline Biara Sub Kontrak & - & $=$ & - \\
\hline TOTAL & $26.193,910.28$ & 28.848 .517 .68 & 28970.181 .94 \\
\hline
\end{tabular}

Sumber : Data Primer Diolah

Berdasarkan hasil analisis data diatas. dapat disimpulkan bahwa pola produksi moderat yang diterapkan PT Satyaloka Tirta Amerta belum efisien, karena pola produksi moderat menghasilkan biaya paling tinggi diantara ketiga pola produksi yang lain.

\section{PENUTUP}

\section{KESIMPULAN}

Berdasarkan hasil analisis data dan pembahasan, maka didapat kesimpulan hasil penelitian mengenai penentuan pola produksi pada PT Satyaloka Tirta Amerta Bangli sebagai berikut:

Pola produksi yang selama ini diterapkan dalam perusahaan adalah pola produksi moderat karena jumlah produksi dalam beberapa periode tertentu konstan dan dalam periode tertentu mengalami kenaikan untuk konstan kembali.

Pola produksi yang selama ini diterapkan dalam perusahaan adalah pola produksi moderat dan melihat hasil analisis data yang ada, dengan melihat tambahan biaya yang dikeluarkan. ternyata penerapan pola produksi moderat pada PT. Satyaloka Tirta Amerta belum efisien karena pola produksi moderat merupakan pola produksi yang memiliki biaya tambahan atau total incremental cost yang paling tinggi untuk tahun 2018. 


\section{SARAN-SARAN}

Berdasarkan hasil analisis data dalam kaitannya dengan pemilihan pola produksi yang paling efisen dan tepat pada PT Satyaloka Tirta Amerta, maka penulis memberikan saran yang mungkin bermanfaat bagi perusahaan. Adapun saran-saran tersebut adalah :

Sebaiknya perusahaan selalu mengadakan analisis biaya tambahan untuk mengetahui pola produksi yang efisien bagi perusahaan.

Sebaiknya dalam kegiatan berproduksi perusahaan perlu menentukan pola produksi yang paling tepat yaitu pola produksi konstan agar dapat memenuhi permintaan konsumen atau pasar yang berfluktuasi secara terus - menerus. Dengan menggunakan pola produksi konstan, perusahaan dapat menekan biaya tambahan yang dikeluarkan, sehingga dapat meminimalkan biaya produksi. Maka pola produksi konstan perlu diterapkan di PT. Satyaloka Tirta Amerta untuk periode yang akan datang.

\section{DAFTAR PUSTAKA}

Ahyari, Agus. (1983). Managemen Produksi Perencanaan Sistem Produksi. ed 3:

BPFE Yogyakarta.

Ahyari, Agus. (1995). Manajemen Produksi Perencanaan Sistem Produksi. Edisi

Empat. Cetakan Keempat : BPFE Yogyakarta.

Ahyari, Agus. (2003). Manajemen Produksi Perencanaan Sistem Produksi. Edisi Keempat : BPFE Yogyakarta.
Arikunto, Suharsimi. (1998). Prosuder Penelitian Suatu Pendekatan Praktek. Jakarta PT. Rineka Cipta.

Assauri, Sofjan. (2008). Manajemen Produksi dan Operasi. Edisi Revisi: FE Universitas Indonesia.

DH, Basu Swastha dan Ibnu Sukotjo W. (1997). Pengantar Bisnis Modern. Edisi Ketiga. Cetakan Kelima Liberti : Yogyakarta.

Gitosudarmo, Indrio. (1999). Sistem Perencanaan dan Pengendalian Produksi. Edisi Revisi. BPFE UGM: Yogyakarta.

Gitosudarmo, Indriyo. (2007). Manajemen Operasi Edisi Tiga : BPFE Yogyakarta

Handoko T. Hani. (1990). Dasar-dasar Manajemen Produksi dan operasi. BPFE

Handoko T. Hani. (1995). Dasar-dasar Manajemen Produksi dan Operasi. Edisi Satu. Cetakan Kesembilan. BPFE: Yogyakarta.

Handoko T. Hani. (2003). Dasar-Dasar Manajemen Produksi dan Operasi. Edisi Pertama. Cetakan Ke Dua Belas. BPFE: Yogyakarta.

Mulyadi, (1984). Akuntansi Biaya untuk Manajemen.Ghalia Indonesia.

Reksohadipratdjo, Sukanto dan Indriyo Gitosudarmo. (1997). Manajemen 